\title{
Development of an Enhanced Recovery After Surgery (ERAS) approach for lumbar spinal fusion
}

\author{
Michael Y. Wang, MD, ${ }^{1}$ Peng-Yuan Chang, MD, ${ }^{1}$ and Jay Grossman, MD² \\ Departments of ${ }^{1}$ Neurological Surgery and ${ }^{2}$ Anesthesiology, University of Miami Miller School of Medicine, Miami, Florida
}

OBJECTIVE Over the past decade, Enhancing Recovery After Surgery (ERAS) programs have been implemented throughout the world across multiple surgical disciplines. However, to date no spinal surgery equivalent has been described. In this report the authors review the development and implementation of a "fast track" surgical approach for lumbar fusion.

METHODS The first 42 consecutive cases in which patients were treated with the new surgical procedure were reviewed. A combination of endoscopic decompression, expandable cage deployment, and percutaneous screw placement were performed with liposomal bupivacaine anesthesia to allow the surgery to be performed without general endotracheal anesthesia.

RESULTS In all cases the surgical procedure was performed successfully without conversion to an open operation. The patients' mean age $( \pm S D$ ) was $66.1 \pm 11.7$ years, the male/female ratio was $20: 22$, and a total of 47 levels were treated. The mean operative time was $94.6 \pm 22.4$ minutes, the mean intraoperative blood loss was $66 \pm 30 \mathrm{ml}$, and the mean hospital length of stay was $1.29 \pm 0.9$ nights. Early follow-up showed a significant improvement in the mean Oswestry Disability Index score (from $40 \pm 13$ to $17 \pm 11, p=0.0001$ ). Return to the operating room was required in 2 cases due to infection and in 1 case due to cage displacement. An iterative quality improvement program demonstrated areas of improvement, including steps to minimize infection, improve postoperative analgesia, and reduce cage osteolysis.

CONCLUSIONS ERAS programs for improving spinal fusion surgery are possible and necessary. This report demonstrates a first foray to apply these principles through 1) a patient-focused approach, 2) reducing the stress of the operation, and 3) an iterative improvement process.

https://thejns.org/doi/abs/10.3171/2016.9.SPINE16375

KEY WORDS minimally invasive; spondylolisthesis; lumbar spine; interbody fusion; bone morphogenetic protein; BMP; expandable cage; endoscopy; anesthesia; pedicle screw; percutaneous; ERAS

$\mathrm{T}$ HE Enhancing Recovery After Surgery (ERAS) movement began in Denmark as a practice concept integrating multidisciplinary, perioperative care programs. Previously known as "fast-track surgery" or "enhanced recovery programs," it started to gain ground in the 1990s by aiming to reduce the length of hospitalization after elective abdominal surgery through integrated approaches to maintain cardiovascular, pulmonary, neurological, gastrointestinal, and endocrine homeostatic functions. ${ }^{9,10}$ Traditionally, a patient's surgical journey has been broken into different stages during which various care protocols are carried out by individual teams (e.g., outpatient team, preoperative staff, anesthesia team, surgical team, and ward care staff). Even with optimal execution of these protocols, the quality of care delivered may be diminished by lack of coordination between these teams?

To combat these shortcomings, ERAS protocols are designed to have every caregiver involved in the patient's entire journey and require interactive team audits on a regular basis. Further benefits include the reduction of metabolic stress from surgery, maintenance of fluid homeostasis, and integrated postoperative care. ${ }^{12}$ For example, the combined ERAS protocol items in the case of colorectal surgery begin with preadmission information and counseling, reduced bowel preparation, pre-anesthesia medication, minimally invasive surgical procedures, postoperative analgesia, and early mobilization. ${ }^{11}$ After gaining public attention in the last decade, more recent ERAS research has focused on

ABBREVIATIONS ERAS = Enhancing Recovery After Surgery; FDA = Food and Drug Administration; MIS = minimally invasive surgery; MIS TLIF = minimally invasive TLIF; ODI = Oswestry Disability Index; QI = quality improvement; rhBMP-2 = recombinant human bone morphogenetic protein-2; TLIF = transforaminal interbody fusion. SUBMITTED March 31, 2016. ACCEPTED September 12, 2016.

INCLUDE WHEN CITING Published online December 23, 2016; DOI: 10.3171/2016.9.SPINE16375. 
the immune response after surgery and new approaches to prevent postoperative inflammation, including the proper selection of anesthetic agents, goal-directed fluid therapy, and the application of minimally invasive surgery. ${ }^{6}$

Another aspect of ERAS has been its data-driven quality improvement approach. This has allowed for iterative improvements in surgical care based upon a continuous examination of the effects of changes to the surgical protocol. Thus, ERAS processes are always undergoing revision in a quest to optimize procedures and practices. In a sense, procedures undergo a constant and directed evolution toward improvement from multiple perspectives, including the patient, surgeon, hospital, payor, and regulatory stakeholders.

The success of ERAS has been obvious and well demonstrated by the proliferation of programs both geographically and by specialty. Although the movement began in Western Europe, it has now spread to virtually all industrialized nations in one form or another. Similarly, ERAS initiatives have been developed for numerous surgical subspecialties. There is now an international ERAS conference, and a society has been founded to assist centers in implementing or improving their programs.

Nevertheless, to date there have been no spine ERAS programs implemented. Given that spinal fusion surgeries can be painful, morbid, and costly, the implementation of a spine ERAS program would be most welcome. In our institution we have been developing a lumbar spinal fusion program incorporating the principles of ERAS in an effort to improve patient outcomes and reduce complications. ${ }^{19}$ This report summarizes our initial experience with the first iteration of our program.

\section{Methods \\ ERAS Program Components}

The development of an ERAS protocol at the University of Miami began with an exploration of steps along the patient's journey through a surgical procedure. This includes not only the procedure itself but also aspects of the preoperative and postoperative journey as shown in Table 1 and Fig. 1. In our initial development (Version 1.0) of a fast-track spinal fusion procedure, we chose to focus on the operative intervention itself. We focused on developing a modified minimally invasive transforaminal interbody fusion (MIS TLIF) operation due to the widespread application of this technique, its versatility for treating diverse lumbar spine pathologies, and its existing development as a minimally invasive surgery (MIS) approach. The first iteration of the ERAS MIS TLIF differed from standard open surgery because of 6 technological components. ${ }^{19}$ These components, as well as their potential advantages, disadvantages, and Food and Drug Administration (FDA) labeling, are shown in Table 2. Although pre- and postoperative components of a mature ERAS program are an integral portion of a complete program, we have only recently begun to explore this important area, and this series does not incorporate any specific changes in these areas.

\section{Procedural Steps}

The procedure has been described in a previous publi- cation. ${ }^{19}$ With the patient prone on a Jackson table, careful monitoring by the anesthesiologist is necessary during the operation. Supplemental oxygen is given via face mask or nasal cannula, but no laryngeal access is used. No Foley catheter is placed. The patient is sedated with a combination of propofol and ketamine administered intravenously, titrating to moderate sedation. No narcotic medications are given, and no spinal, epidural, or regional analgesia is used. The surgeon is thus able to monitor whether there is any contact or tension with the neural structures, as the patient will respond with complaints of lower-extremity pain. In addition, this eliminates untoward side effects of general anesthesia, including nausea, dysphagia, and memory loss.

Kambin's triangle is unilaterally entered using a spinal needle with the assistance of local injections of Marcaine (bupivacaine hydrochloride and epinephrine). This allows successive dilation of the access site to a final 8-mm outer diameter working channel (JoiMax Inc). The traversing and exiting nerve roots are identified using the working channel endoscope, and any compressive bony or cartilaginous pathology can be removed under direct visualization. The endoscope does allow for direct removal of disc material, osteophytes, part of the superior articular process of the facet, and ligamentum flavum. The disc space is cleaned, and the bony endplates are prepared for interbody fusion. This is accomplished utilizing a combination of pituitary rongeurs, curettes, and stainless steel brushes.

Following disc removal, $2.1 \mathrm{mg}$ of rhBMP-2 (recombinant human bone morphogenetic protein-2, InFuse, Medtronic Sofamor Danek) is placed into the anterior disc space as far away from any neural structures as possible. This is followed by placement of an Optimesh (Spineology) cage. The mesh expandable cage is filled internally with premachined allograft matrix to increase interbody height and reduce any spondylolisthesis (Fig. 2). Bilateral pedicle screws are then inserted percutaneously under fluoroscopic guidance. The 4 or 6 (for a 2-level fusion) access sites for the pedicle screws are first injected with a total of $20 \mathrm{ml}$ of Exparel. This is diluted 1:2 to $40 \mathrm{ml}$ of total volume, then divided evenly between the 4 screw insertion tracts. The pedicle screws are then connected using bilateral rods placed subfascially. Each of the 5 small incisions are then closed with Monocryl suture. It should be noted that the use of InFuse, Optimesh, and Exparel in this application is off-label for the US FDA.

\section{Patient Series}

A consecutive case series involving the first 42 patients treated with the ERAS MIS TLIF was analyzed retrospectively. Selection criteria did not change for these patients as compared with standard open or conventional MIS TLIF. All patients had either a spondylolisthesis or a severely degenerated disc with nerve root impingement. In addition, all patients had some component of radiculopathy from neural compression as well as back pain from instability. Patients who would otherwise have been treated without fusion were not candidates for this procedure.

All data were collected prospectively. The patients were evaluated for baseline demographics, Charlson Comorbidity Index, pathology being treated, surgical level, blood 
TABLE 1. Spinal ERAS recommendations

\begin{tabular}{|c|c|c|}
\hline Items & $\begin{array}{l}\text { Summary and } \\
\text { Recommendation }\end{array}$ & $\begin{array}{l}\text { Responsible } \\
\text { Team Member }\end{array}$ \\
\hline $\begin{array}{l}\text { Preadmission counsel- } \\
\quad \text { ing }\end{array}$ & $\begin{array}{l}\text { Patients should receive oral and written information to describe what they should expect and what their } \\
\text { role is in recovery. }\end{array}$ & Surgeon \\
\hline $\begin{array}{l}\text { Preoperative enteral } \\
\text { nutrition }\end{array}$ & $\begin{array}{l}\text { All patients are encouraged to have improved enteral nutrition. Increased protein uptake is recommend- } \\
\text { ed, especially for underweight patients, and patients at risk for constipation are treated preoperatively. }\end{array}$ & Nurses \\
\hline $\begin{array}{l}\text { Preoperative fasting \& } \\
\text { carbohydrate loading }\end{array}$ & $\begin{array}{l}\text { The duration of preoperative fasting (NPO) is } 8 \mathrm{hrs} \text { for liquids and } 12 \mathrm{hrs} \text { for solid food. Routine carbohy- } \\
\text { drate loading is suggested. }\end{array}$ & Nurses \\
\hline $\begin{array}{l}\text { Antithrombotic prophy- } \\
\text { laxis }\end{array}$ & The application of compression stockings and intermittent pneumatic compression is suggested. & Nurses \\
\hline $\begin{array}{l}\text { Antimicrobial prophylax- } \\
\text { is \& skin preparation }\end{array}$ & $\begin{array}{l}\text { Routine prophylaxis with first-generation cephalosporin } 1 \mathrm{hr} \text { before incision is recommended. Vaccination } \\
\text { for MRSA is suggested. }\end{array}$ & Surgeon \\
\hline Anesthesia protocol & $\begin{array}{l}\text { No general anesthesia is recommended. Long-acting opioids and anesthetic agents should be avoided. } \\
\text { Proper, short-duration sedation may be needed. }\end{array}$ & Anesthetist \\
\hline Local analgesia & $\begin{array}{l}\text { Skin blocks by local anesthesia are recommended for every skin incision. Long-acting liposomal bupiva- } \\
\text { caine is used for the screw entry sites. }\end{array}$ & Surgeon \\
\hline $\begin{array}{l}\text { Minimally invasive } \\
\text { spinal surgery }\end{array}$ & $\begin{array}{l}\text { Minimally invasive spinal procedures are required, including endoscopic decompression and deployment } \\
\text { of expandable cages for interbody fusion. Percutaneous instrumentation of pedicle screws is needed. }\end{array}$ & Surgeon \\
\hline Osteobiologics & $\begin{array}{l}\text { Routine application of osteobiologic adjuvants to promote fusion are used, eliminating the need for bone } \\
\text { graft harvesting and promoting the likelihood of a successful arthrodesis. }\end{array}$ & Surgeon \\
\hline Surgical drainage & Routine use of surgical drains is not recommended. & Surgeon \\
\hline $\begin{array}{l}\text { Avoiding hypothermia \& } \\
\text { hypotension }\end{array}$ & Intraoperative maintenance of normothermia and blood pressure is routinely performed. & Anesthetist \\
\hline Fluid balance & $\begin{array}{l}\text { Noninvasive cardiac output monitoring is used for minimally invasive monitoring of the fluid status during } \\
\text { operation. Hypovolemia should be avoided. }\end{array}$ & Anesthetist \\
\hline Urinary drainage & Avoidance of urinary catheterization reduces the likelihood of postop urinary retention. & Surgeon \\
\hline Postop analgesia & $\begin{array}{l}\text { Gabapentin, tramadol, and acetaminophen are frequently used, to favor less potential risk for bone fu- } \\
\text { sion. Effective early pain control reduces patient anxiety and fear, promoting rapid mobilization. }\end{array}$ & Nurses \\
\hline Postop nutrition & Patients are encouraged to have oral intake at will after recovery from surgery. & Nurses \\
\hline Early mobilization & $\begin{array}{l}\text { Early mobilization using a brace is recommended. No bending or weight lifting for patients who have had } \\
\text { fusion surgery. }\end{array}$ & Nurses \\
\hline Audit & Systemic audit is recommended for assessing impact and may influence compliance. & Multidisciplinary \\
\hline
\end{tabular}

MRSA = methicillin resistant Staphylococcus aureus; NPO = nil per os.

loss, hospital length of stay, and perioperative complications. Clinical metrics included Oswestry Disability Index (ODI), SF-36, and EQ-5D scores, which were obtained before surgery and at 6 weeks, $3,6,12$, and 24 months postoperatively. Preoperative and postoperative metrics were analyzed. Iterative improvement protocols were instituted based upon outcomes and complications during the perioperative (1st 2 weeks) and early (1st 3 months), intermediate (1 year), and long-term (2 years) follow-up periods.

\section{Results}

\section{Patient Population}

A total of 42 patients were treated over a 22-month period. Clinical and demographic data are shown in Table 3. All patients underwent either a 1- or 2-level unilateral TLIF surgery successfully and without conversion to an open surgery. The average age was $66.1 \pm 11.7$ years (range 28-87 years). The male/female ratio was 20:22. All patients had severe disc height collapse, and 60\% had a Grade I spondylolisthesis. Given the predominance of degenerative spondylolisthesis cases in this study, L4-5 was the most commonly treated level. The mean operative time ( \pm SD) was $94.6 \pm 22.4$ minutes (range 60-140 minutes), and intraoperative blood loss was $66 \pm 30 \mathrm{ml}$ (range 30-190 ml). The mean hospital length of stay was $1.29 \pm 0.9$ nights. The vast majority of patients were discharged on postoperative Day 1 . However, there were exceptions such as 1 patient who had no family or social support and thus was not discharged home for 5 days. One patient was lost to follow-up, and the mean duration of follow-up was 10 months.

\section{Clinical Outcome Measures}

All patients underwent surgery without any intraoperative events related to anesthesia, over-sedation, medical events, or sentinel surgical events. All patients were able to tolerate the entirety of the procedure. Postoperatively, pain control was successful with standard regimens of narcotic analgesics, and all patients were ambulatory on either the day of surgery or the day after surgery. Preoperative scores on clinical outcome measures were compared with scores 


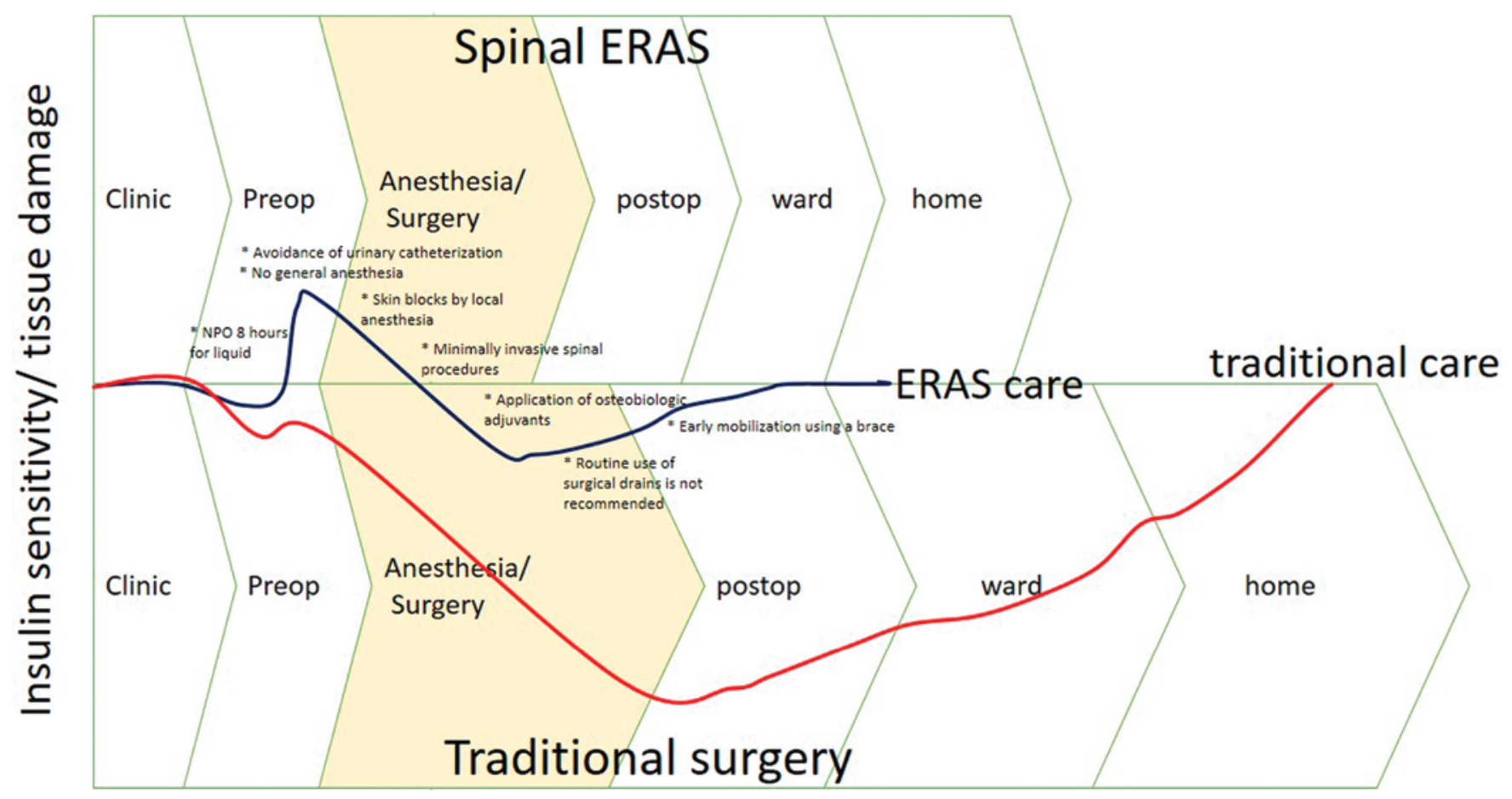

FIG. 1. Roadmap of a patient's journey through an ERAS spinal fusion surgery compared with traditional surgery. Figure is available in color online only.

at 3 months' follow-up, as complete data were available for $76 \%$ of patients at this early time point. The mean ODI score improved from $40 \pm 13$ to $17 \pm 11(p=0.0001)$, and this change was statistically significant.

\section{Radiographic Results}

Radiographic imaging included flexion-extension radiographs at 3,6, and 12 months following surgery. While CT scanning was not obtained in all cases to demonstrate arthrodesis, patients were observed clinically to assess for any signs or symptoms of a nonunion, including persistent or worsening back pain. Any radiographic evidence suggestive of a nonunion, such as hardware loosening or ab- normal motion was investigated with CT scanning. Using these criteria, there were no cases of delayed nonunion. There was no hardware loosening, breakage, or dislodgement. However, 1 patient had an early graft migration at 2 months after surgery, which was treated with a revision operation via the anterior approach.

\section{Complications}

In this series there were no intraoperative complications related to anesthesia. However, 3 patients required a return to the operating room. The first was the case of cage displacement described above. The other two were patients early in the series who developed an infection

TABLE 2. Lumbar spine fusion ERAS components

\begin{tabular}{lccc}
\hline \multicolumn{1}{c}{ Component } & Advantages & Disadvantages & FDA Clearance \\
\hline Working channel endoscope & $\begin{array}{c}\text { 8-mm incision, allows for a formal discecto- } \\
\text { my, clear visualization }\end{array}$ & $\begin{array}{c}\text { Limited decompression capability, capital } \\
\text { equipment costs, learning curve }\end{array}$ & On-label \\
\hline Anesthesia w/o intubation & $\begin{array}{c}\text { Patient neuromonitoring, limited anesthetic } \\
\text { side effects, more normal homeostasis }\end{array}$ & $\begin{array}{c}\text { Limited working time, airway not secured, } \\
\text { close airway monitoring needed }\end{array}$ \\
\hline Expandable cage & $\begin{array}{c}\text { Implantable through 8 mm, improves } \\
\text { foraminal space, reduces listhesis }\end{array}$ & $\begin{array}{c}\text { Cage resorption and subsidence, risks of bone } \\
\text { allograft, not available in all countries }\end{array}$ & Off-label \\
\hline BMP & $\begin{array}{c}\text { Robustly promotes osteogenesis, in wide- } \\
\text { spread use, no need for autograft }\end{array}$ & $\begin{array}{c}\text { Heterotopic bone formation, questions of } \\
\text { teratogenesis, cost }\end{array}$ \\
\hline Small-caliber percutaneous screws & $\begin{array}{c}\text { Premium implant cost } \\
\text { Off-label }\end{array}$ \\
\hline Liposomal bupivacaine & 72 hrs of local analgesia, reduces narcoticl \\
& NSAID usage & Cost, risk of intrathecal injection & On-label \\
\hline
\end{tabular}

$\mathrm{BMP}=$ bone morphogenetic protein; NSAID = nonsteroidal anti-inflammatory drug. 


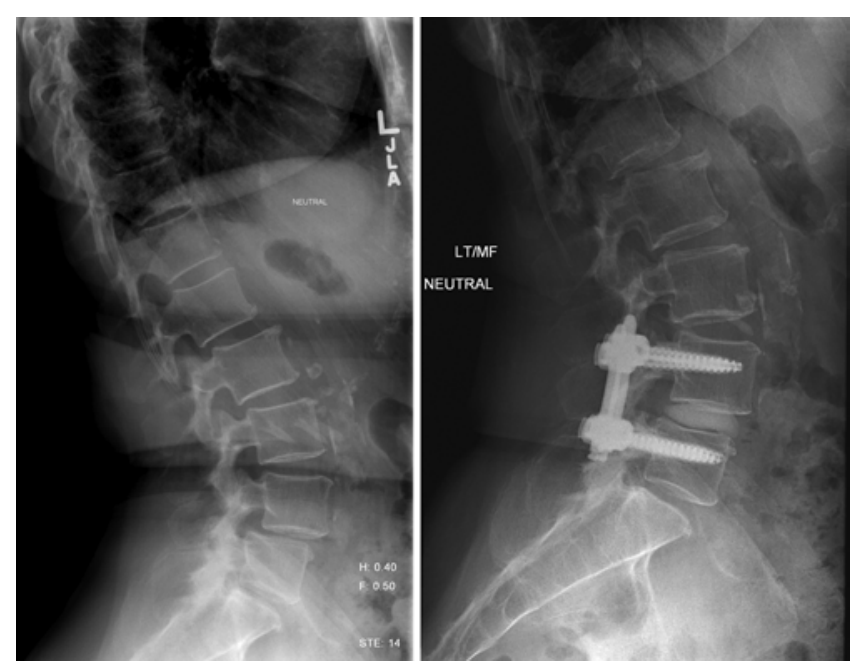

FIG. 2. Representative case involving a patient with an L4-5 Grade I spondylolisthesis. Preoperative (left) and postoperative (right) radiographs obtained before and after an interbody fusion procedure with interbody cage and bilateral pedicle screw placement performed using the ERAS technique.

of the interbody graft. The presentation was with sepsis, which was treated effectively with an incision and drainage followed by intravenous antibiotic therapy. Other complications included 1 case of atrial fibrillation, treated medically, and 1 case of an upper-extremity deep venous thrombosis, treated without anticoagulation. Two patients developed transient radiculitis due to manipulation of exiting nerve roots during surgery.

\section{Iterative Improvement of Surgery}

The patient's journey following a surgical procedure is outlined in Table 4. While it is imperative to have longterm follow-up for patients undergoing spinal fusion procedures, critical information can also be gleaned from earlier follow-up. Earlier follow-up can be arbitrarily divided into 4 time periods: perioperative (first 2 weeks), early (first 3 months), intermediate (1 year), and long term (2 years). Specific outcome measures and complications can be identified at each time period. In our study, targeted iterative improvements based on earlier outcomes (before 2 years) have already resulted in meaningful data to drive the improvement process.

During the perioperative period it was identified that the method of liposomal bupivacaine injection has a major impact on postoperative pain control. In cases in which injection of this agent was not under pressure, pain control was poor. These cases occurred when the pedicle screws were placed prior to injection. The soft tissue opening prevented injection under high pressure. Thus, this agent is now first injected while the soft tissue envelope is intact and not disrupted, allowing for a high-pressure injection along the screw tract. This was an important point because of the limited ability of liposomal bupivicaine to diffuse through soft tissues.

During the early follow-up period (first 3 months), it was identified that 2 patients had interbody-space infec-
TABLE 3. Summary of clinical and demographic characteristics of patients

\begin{tabular}{|c|c|}
\hline Characteristic & Value \\
\hline \multicolumn{2}{|l|}{ Age in yrs } \\
\hline Mean & $66.1 \pm 11.7$ \\
\hline Range & $28-87$ \\
\hline Sex, $\%$ male & $48 \%$ \\
\hline $\mathrm{CCl}$, mean & $2.04 \pm 1.3$ \\
\hline \multicolumn{2}{|l|}{ No. of levels treated } \\
\hline 1 & 37 \\
\hline 2 & 5 \\
\hline \multicolumn{2}{|l|}{ Level treated } \\
\hline L1-2 & 1 \\
\hline L2-3 & 1 \\
\hline L3-4 & 6 \\
\hline L4-5 & 36 \\
\hline L5-S1 & 3 \\
\hline Total no. of levels treated & 47 \\
\hline \multicolumn{2}{|l|}{ Op time in mins } \\
\hline Mean & $94.6 \pm 22.4$ \\
\hline Range & $60-140$ \\
\hline \multicolumn{2}{|l|}{ Intraop blood loss in ml } \\
\hline Mean & $66 \pm 30$ \\
\hline Range & $30-190$ \\
\hline \multicolumn{2}{|l|}{ LOS, no. of nights } \\
\hline Mean & $1.29 \pm 0.9$ \\
\hline Range & $1-5$ \\
\hline
\end{tabular}

LOS = length of stay in hospital.

Values represent numbers of patients unless otherwise indicated. Mean values are presented with standard deviations.

tions. Examination of the central processing procedures revealed that potential improvements in cleaning and processing the endoscopic equipment could be instituted through education. We also began adding vancomycin (1 g) to the irrigant used during the endoscopic portion of the procedure. After the institution of these changes we saw no more interbody-space infections.

During the intermediate follow-up period (first year) we began observing some cases of interbody cage subsidence. This was not vertebral endplate subsidence, but rather dissolution of some of the interbody cage, which is composed largely of cadaveric allograft. In the early series, we combined rhBMP-2 with the allograft, which was placed inside the cage. Following the identification of this radiographic (but not clinically relevant) finding, we began placing the osteobiologic agent anterior to the cage. The evaluation of this intraoperative change is ongoing. Long-term follow-up data collection is ongoing.

\section{Discussion}

\section{Why Is an ERAS Approach Necessary?}

The impetus for the ERAS movement was a clear need to improve the efficacy, reduce the morbidity, and 
TABLE 4. Iterative improvement components

\begin{tabular}{|c|c|c|c|c|}
\hline \multirow[b]{2}{*}{ Description } & \multirow[b]{2}{*}{ Periop Period } & \multicolumn{3}{|c|}{ Follow-Up } \\
\hline & & Early & Intermediate & Longer Term \\
\hline Time period & 1st 2 wks & $1 \mathrm{st} 3 \mathrm{mos}$ & $1 s t y r$ & $>2 \mathrm{yrs}$ \\
\hline Sample size & 42 patients & 34 patients & 20 patients & 4 patients \\
\hline $\begin{array}{l}\text { Outcomes to be mea- } \\
\text { sured and complica- } \\
\text { tions to be monitored }\end{array}$ & $\begin{array}{l}\text { Anesthetic protocol, postop } \\
\text { nausea, pain control, time to } \\
\text { mobilization, LOS }\end{array}$ & $\begin{array}{l}\text { Wound infections, readmissions, hard- } \\
\text { ware misplacement, implant migration, } \\
\text { postop radiculitis }\end{array}$ & $\begin{array}{l}\text { Clinical improvement, } \\
\text { graft subsidence }\end{array}$ & $\begin{array}{l}\text { Fusion rates, } \\
\text { ASD }\end{array}$ \\
\hline Primary data source & Hospital record & Clinic notes & Survey instruments & $\begin{array}{l}\text { Radiographic } \\
\text { imaging }\end{array}$ \\
\hline Findings & $\begin{array}{l}\text { No anesthetic complications, pain } \\
\text { control dependent on method of } \\
\text { liposomal bupivacaine injection }\end{array}$ & $\begin{array}{l}\text { Deep infection in } 2 \text { patients, no unwar- } \\
\text { ranted readmissions }\end{array}$ & $\begin{array}{l}\text { Excellent clinical improve- } \\
\text { ment, mild subsidence } \\
\text { seen in some cases }\end{array}$ & NA \\
\hline Changes implemented & $\begin{array}{l}\text { Continuation of propofol/ketamine } \\
\text { protocol, injection of liposomal } \\
\text { bupivacaine under high pres- } \\
\text { sure for all screw tracts }\end{array}$ & $\begin{array}{l}\text { Education of staff on cleaning and ster- } \\
\text { ilization of endoscopy equipment and } \\
\text { use of vancomycin in endoscopic irrig- } \\
\text { ant, continuation of postop education }\end{array}$ & $\begin{array}{l}\text { Placement of BMP ante- } \\
\text { rior to instead of inside } \\
\text { interbody graft }\end{array}$ & NA \\
\hline Result & $\begin{array}{l}\text { More consistent postop analgesic } \\
\text { usage }\end{array}$ & Decreased infection rate & Pending & NA \\
\hline
\end{tabular}

ASD = adjacent-segment disease; $N A$ = not applicable.

minimize the costs associated with surgical interventions. While the initial efforts focused on colorectal surgery, the basic principles have now been applied to multiple surgical disciplines. These principles have included: 1) a focus on the patient and the patient experience; 2) a multidisciplinary team approach; 3) efforts to reduce pain, morbidity, and recovery time; and 4) a data-driven iterative improvement process. This report represents our initial foray into applying ERAS principles in spinal fusion. We have felt that such a program is desperately needed given the variability in outcomes, high costs of care, and negative perceptions of lumbar spinal fusion in general.

\section{How Spinal ERAS Works}

The core of the ERAS surgical paradigm, whether for removing an abdominal lesion or decompressing neural elements, is to minimize the stress (physiological, psychological, economic, and social) that surgery places on the patient. ${ }^{13,15,17}$ In spinal fusion surgery, two of the main stressors are the anesthesia and postoperative pain. We have attempted to avoid general anesthesia and use local analgesia in combination with deep sedation to mitigate the negative effects associated with general endotracheal anesthesia. These negative effects include hemodynamic instability, cardiac stress, memory loss, and postoperative nausea. With regard to postoperative pain, it is well understood that pain reduces mobility, increases anxiety, and requires significant pharmacotherapy. With the use of ultraminimally invasive techniques to reduce tissue trauma ${ }^{6,7,16}$ in concert with long-acting local anesthetics, patients experience far less pain at the surgical site, mobilize quickly, and are discharged earlier.

In spinal surgery, we have found that changes in the anesthesia protocol and minimally invasive surgical techniques work synergistically to improve the patient experience. For example, only a truly minimally invasive procedure can be safely performed without general anesthesia. This, in turn, reduces the negative effects of the anesthesia. For example, having the patient autoregulate blood pressure reduces the need for invasive blood pressure monitoring and additional pharmacological intervention to raise or lower the blood pressure. Such practices may be especially beneficial in patients with advanced age or multiple comorbidities.,16,21

\section{Previous Case Series}

While rapid recovery following minimally invasive decompression surgery has been achieved, obtaining these results with fusion surgery has been more challenging. Previous reports have shown accelerated recovery after lumbar fusion surgery utilizing a combination of MIS with an aggressive pain management protocol. ${ }^{3}$ Some authors have attempted to use unilateral screw fixation in an effort to reduce pain and blood loss, thus allowing lumbar fusion to be performed as an outpatient procedure. ${ }^{4}$ Others have advocated using regional analgesia, such as spinal or epidural infusions..$^{2,5,8,14}$ However, none of these methods has become popular, either because the surgical intervention might be viewed as compromised, or because the use of regional analgesia is viewed as impractical or as a limitation to neuromonitoring.

Regardless, these case series have largely been driven by attempts to move fusion surgery into the ambulatory surgery center. In this report, our approach has not been focused on early discharge, but rather on the ERAS philosophy of improving recovery and the patient experience. While the surgical procedure we describe can clearly be performed in an ambulatory surgery center, that is not our primary goal. We believe that the basic tenets of open surgery apply, including: 1) performing surgery in clearly indicated cases, 2) improving patient outcomes through neural decompression and spinal stabilization, 3) achieving a successful arthrodesis, and 4) minimizing complications. 


\section{Initial Experience (Version 1.0)}

This series represents our efforts to use a combination of several techniques and technologies to achieve a more rapid and less painful recovery after lumbar spinal fusion surgery. The use of endoscopy and percutaneous screws reduces the amount of soft tissue disruption to the extent that the intervention can be tolerated without general anesthesia. Expandable cages allow for efficient placement of an interbody device to allow for fusion through Kambin's triangle. This also permits indirect neural decompression by restoring intervertebral height. Osteobiologics are necessary to promote fusion through such a small corridor. Use of conscious sedation avoids the more severe side effects of general anesthesia, and it also allows for live neurological monitoring through patient feedback. Finally, liposomal bupivacaine provides prolonged local analgesia during the first 3 days after surgery, which is typically the most painful time period. These component techniques have all been previously applied clinically with success, but it is the combination of them that makes this series unique.

In this case series we were able to demonstrate that use of this multimodal method allowed patients to be discharged rapidly from the hospital following single-level MIS TLIF surgery. The hospital stay was reduced substantially. This reflects a reduction of over 2 hospital days on average (3.9 vs 1.29 days) compared with our previous publications of "standard" MIS TLIF. 18,20 The blood loss was also reduced substantially, primarily through the use of working channel endoscopy to perform the neural decompression and discectomy.

\section{Iterative Improvement Processes}

A fundamental tenet of ERAS is a data-driven quality improvement (QI) process. Realizing the deficiencies that exist with present methods and technologies in spinal surgery, we were able to quickly apply this method to our surgical service. It should be recognized that long-term data are essential. However, the long cycle of follow-up and delayed feedback loop of any project requiring data to have a minimum of 2-year follow-up would in reality require iterative time periods on the order of a decade to provide meaningful recommendations, changes, and validation. In addition, it is clear that a wealth of clinical and radiographic data are available at the perioperative, early, and intermediate time periods, even for fusion operations (e.g., infection, length of stay, CSF leak). Thus, these earlier data are viewed as complementary to, and not as a substitute for, longer-term follow-up.

Within the first 2 years of our instituting this QI process, 3 substantive changes have already occurred. The first involved a process problem related to infection. This problem was resolved with a rigorous examination of sterile core processing procedures as well as use of antibiotics in the endoscopic irrigant fluid. The second was a surgeon technique problem related to the injection of liposomal bupivacaine. This problem was improved with an alteration to the injection method, which requires adequate pressure for dispersion through soft tissues. The third was related to osteobiologic-related osetolysis of the allograft and is currently under investigation. Due to the longer-term fol- low-up needed for this third problem, the final outcome requires a longer follow-up time period.

Ultimately, we plan to institute many of the other critical components that have made ERAS programs in other subspecialties successful. This will include patient education, preoperative nutritional supplementation, standardized mobilization practices, and monitoring of outcome measures beyond standard spine metrics.

\section{Study Limitations}

This study has significant limitations. It serves as the first English-language publication outlining an action plan for an ERAS spinal fusion protocol. Accordingly, however, the long-term follow-up data are insufficiently powered to draw definitive conclusions as to efficacy, safety, and fusion rates. Ultimately, this procedure must be able to achieve fusion rates equivalent to open lumbar fusion to be deemed acceptable, as a failure of arthrodesis will likely result in the ultimate failure of the procedure. Definitive confirmation of arthrodesis using 3D imaging (CT) would also be ideal for demonstrating efficacy. Finally, the generalizability of the procedure is important to ensure that it can be applied in diverse institutions, settings, and surgeons' hands.

\section{Conclusions}

This report describes the first spinal fusion ERAS protocol, focusing largely on our intraoperative improvements. Using a combination of techniques and technologies, we were able to perform lumbar spinal fusions successfully without conversion to more standard methods. While still in its infancy, this technique, with modification, will likely reduce postoperative recovery times, complications, and acute care costs. Future reports will focus on the addition of the pre- and postoperative components of ERAS.

\section{References}

1. American Geriatrics Society Expert Panel on Postoperative Delirium in Older Adults: Postoperative delirium in older adults: best practice statement from the American Geriatrics Society. J Am Coll Surg 220:136-148, 148.e1, 2015

2. Boezaart AP, Eksteen JA, Spuy GV, Rossouw P, Knipe M: Intrathecal morphine. Double-blind evaluation of optimal dosage for analgesia after major lumbar spinal surgery. Spine (Phila Pa 1976) 24:1131-1137, 1999

3. Chin KR, Coombs AV, Seale JA: Feasibility and patientreported outcomes after outpatient single-level instrumented posterior lumbar interbody fusion in a surgery center: preliminary results in 16 patients. Spine (Phila Pa 1976) 40:E36-E42, 2015

4. Eckman WW, Hester L, McMillen M: Same-day discharge after minimally invasive transforaminal lumbar interbody fusion: a series of 808 cases. Clin Orthop Relat Res 472:1806-1812, 2014

5. Elder JB, Hoh DJ, Wang MY: Postoperative continuous paravertebral anesthetic infusion for pain control in lumbar spinal fusion surgery. Spine (Phila Pa 1976) 33:210-218, 2008

6. Hoffmann H, Kettelhack C: Fast-track surgery-conditions and challenges in postsurgical treatment: a review of elements of translational research in enhanced recovery after surgery. Eur Surg Res 49:24-34, 2012

7. Kahokehr A, Sammour T, Zargar-Shoshtari K, Thompson L, 
Hill AG: Implementation of ERAS and how to overcome the barriers. Int J Surg 7:16-19, 2009

8. Kakiuchi M, Abe K: Pre-incisional caudal epidural blockade and the relief of pain after lumbar spine operations. Int Orthop 21:62-66, 1997

9. Kehlet H: Multimodal approach to control postoperative pathophysiology and rehabilitation. Br J Anaesth 78:606617, 1997

10. Kehlet H, Wilmore DW: Multimodal strategies to improve surgical outcome. Am J Surg 183:630-641, 2002

11. Lassen K, Soop M, Nygren J, Cox PB, Hendry PO, Spies $\mathrm{C}$, et al: Consensus review of optimal perioperative care in colorectal surgery: Enhanced Recovery After Surgery (ERAS) Group recommendations. Arch Surg 144:961-969, 2009

12. Ljungqvist O: ERAS-enhanced recovery after surgery: moving evidence-based perioperative care to practice. JPEN J Parenter Enteral Nutr 38:559-566, 2014

13. Ljungqvist O: Jonathan E. Rhoads lecture 2011: Insulin resistance and enhanced recovery after surgery. JPEN J Parenter Enteral Nutr 36:389-398, 2012

14. Matheson D: Epidural anesthesia for lumbar laminectomy and spinal fusion. Can Anaesth Soc J 7:149-157, 1960

15. Ren L, Zhu D, Wei Y, Pan X, Liang L, Xu J, et al: Enhanced Recovery After Surgery (ERAS) program attenuates stress and accelerates recovery in patients after radical resection for colorectal cancer: a prospective randomized controlled trial. World J Surg 36:407-414, 2012

16. Shamji MF, Goldstein CL, Wang M, Uribe JS, Fehlings MG: Minimally invasive spinal surgery in the elderly: does it make sense? Neurosurgery 77 (Suppl 4):S108-S115, 2015

17. Thorell A, Nygren J, Ljungqvist O: Insulin resistance: a marker of surgical stress. Curr Opin Clin Nutr Metab Care 2:69-78, 1999

18. Wang M, Cummock M, Yu Y, Trivedi R: An analysis of the differences in the acute hospitalization charges following minimally invasive vs. open posterior lumbar interbody fusion. J Neurosurg Spine 12:694-699, 2010

19. Wang MY, Grossman J: Endoscopic minimally invasive transforaminal interbody fusion without general anesthesia: initial clinical experience with 1-year follow-up. Neurosurg Focus 40(2):E13, 2016

20. Wang MY, Lerner J, Lesko J, McGirt MJ: Acute hospital costs after minimally invasive versus open lumbar interbody fusion: data from a US national database with 6106 patients. J Spinal Disord Tech 25:324-328, 2012

21. Wang MY, Widi G, Levi AD: The safety profile of lumbar spinal surgery in elderly patients 85 years and older. Neurosurg Focus 39(4):E3, 2015

\section{Disclosures}

Dr. Wang reports being a patent holder with and receiving royalty payments from DePuy Synthes Spine, Inc.; having a consultant relationship with DePuy Synthes Spine, JoiMax USA, K2M, and Aesculap Spine; being on the medical advisory board of Vallum; owning stock in Spinicity; and receiving grants from the Department of Defense.

\section{Author Contributions}

Conception and design: Wang. Acquisition of data: Wang, Chang. Analysis and interpretation of data: Wang. Drafting the article: Wang, Chang. Critically revising the article: Wang, Grossman.

\section{Correspondence}

Michael Y. Wang, Department of Neurological Surgery, Lois Pope Life Center, 1095 NW 14th Terrace, Miami, FL 33136. email: mwang2@med.miami.edu. 